\title{
The Relationship between Waist Circumference and Cecal Intubation Time in Women
}

\author{
Banu Karapolat and Uzer Kucuktulu
}

\begin{abstract}
Objective: To investigate the relationship between waist circumference and cecal intubation time (CIT) in female subjects during colonoscopy.

Study Design: A descriptive study.

Place and Duration of Study: Department of General Surgery, Kanuni Training and Research Hospital, Turkey, from January to September 2016.

Methodology: This study included 61 female subjects who underwent colonoscopy in our clinic. The colonoscopies were performed by a single surgeon. The waist circumferences of all subjects were measured before the procedure with the technique recommended by the WHO. In colonoscopy, the cecal intubation time was recorded for each subject. The results were evaluated statistically and $p<0.05$ was considered significant.

Results: The mean waist circumference was $100.6 \pm 19.0 \mathrm{~cm}$. The mean cecal intubation time was $9.0 \pm 2.7$ minutes. A strong statistically significant negative correlation was found between waist circumference and cecal intubation time $(r=-0.689, p<0.001)$.

Conclusion: The cecal intubation time was found to be significantly shorter in the female subjects with larger waist circumferences.
\end{abstract}

Key Words: Colonoscopy, Cecum, Waist circumference, Cecal intubation time.

\section{INTRODUCTION}

Colonoscopy is recognized as an important examination in patients with intestinal symptoms, in those with iron deficiency, in the differential diagnosis of those with abnormal radiological findings in their colon and rectum, in those who screened positive for colon cancer, and in the monitoring of patients undergoing postpolypectomy or colon cancer treatment, and of those with inflammatory intestinal diseases. ${ }^{1,2}$ Colonoscopy can be used in procedures for treatment such as intervention to bleeding lesions, polypectomy, stent placement and foreign body removal. This feature of colonoscopy makes it superior to radiological methods.

Being an important factor in assessing the performance of a colonoscopy, cecal intubation is absolutely necessary for fault-free colon examination. ${ }^{3}$ Cecal intubation is based on the visualization of the ileocecal valve and appendiceal orifice. Cecal intubation time (CIT) denotes the time required for the colonoscope to travel from the anal region to the cecum. ${ }^{4}$ Rapid cecal intubation should be the goal during colonoscopy. ${ }^{1} \mathrm{CIT}$ is affected by age, female gender, history of abdominal

Department of General Surgery, Kanuni Training and Research Hospital, Trabzon, Turkey

Correspondence: Dr. Banu Karapolat, Department of General Surgery, Kanuni Training and Research Hospital, Trabzon, Turkey

E-mail: banukarapolat@hotmail.com

Received: January 15, 2018; Accepted: June 26, 2018 surgery, poor intestinal cleansing, and the colonoscopy experience of the endoscopist. 4,5

Waist circumference measurement is commonly used in clinical practice for assessing abdominal obesity, and it independently contributes to the prediction of nonabdominal, abdominal subcutaneous, and visceral fat in humans. Smaller waist circumference and fewer visceral fats generally cause prolongations in colonoscopy time. ${ }^{6}$ The purpose of this study was to identify the relationship between waist circumference and CIT in colonoscopy patients.

\section{METHODOLOGY}

This study included 61 female subjects who underwent colonoscopy between January and September 2016 in the endoscopy unit of the General Surgery Clinic in Trabzon Kanuni Training and Research Hospital. Patients to undergo colonoscopy for treatment purposes, those with colostomy, abdominal surgery, insufficient intestinal cleansing, colon cancer, and who did not wish to undergo sedoanalgesia, were excluded from the study. The colonoscopy in subjects was performed by a single surgeon. The subjects were advised to consume liquid food and a lot of water for two days ahead; and given intestinal cleansing using lacsative and enema.

Before the procedure, the waist circumferences of all subjects were measured with a $150-\mathrm{cm}$ non-elastic tape in line with the measurement technique recommended by the WHO. The measurement was done on thin 
clothing while the subjects were standing on a flat surface. Waist circumference measurement was obtained by measuring the circumference passing through the middle point between the lowest rib and the iliac bone. The subjects were told to exhale to let loose their abdominal region during the procedure and the waist circumference measurement was performed at that moment.

The protocol of this study was approved by the local Ethics Committee and all subjects signed a written consent form. The study was conducted in accordance with the principles in the Helsinki Declaration as revised in 2000.

Before starting the colonoscopy, vascular access was established in the subjects and their pulses, arterial tensions, and peripheral oxygen saturations were monitored. All subjects were given nasal oxygen (2 liters/ minute), midazolam (Dormicum ampoule, $50 \mathrm{mg} / 10 \mathrm{ml}$, Roche, Turkey) and meperidine (Aldolan ampoule, 100 $\mathrm{mg} / 2 \mathrm{ml}$, Liba, Turkey) in doses of $0.05 \mathrm{mg} / \mathrm{kg}$ and $0.3 \mathrm{mg} / \mathrm{kg}$, respectively and additional doses were administered when needed by the anesthetist in line with the subject monitoring criteria. All colonoscopy procedures were carried out by a single surgeon. The time was started as soon as entry was made from the anal region with a colonoscope and stopped when the cecum was reached. The CIT of all subjects were recorded. The colonoscopy procedure was completed successfully in all subjects without any complication.

All statistical data analyses were carried out using descriptive statistics and the Pearson's correlation analysis on the SPSS statistics software (SPSS Inc., Chicago, IL, USA), version 15.0. The statistical significance

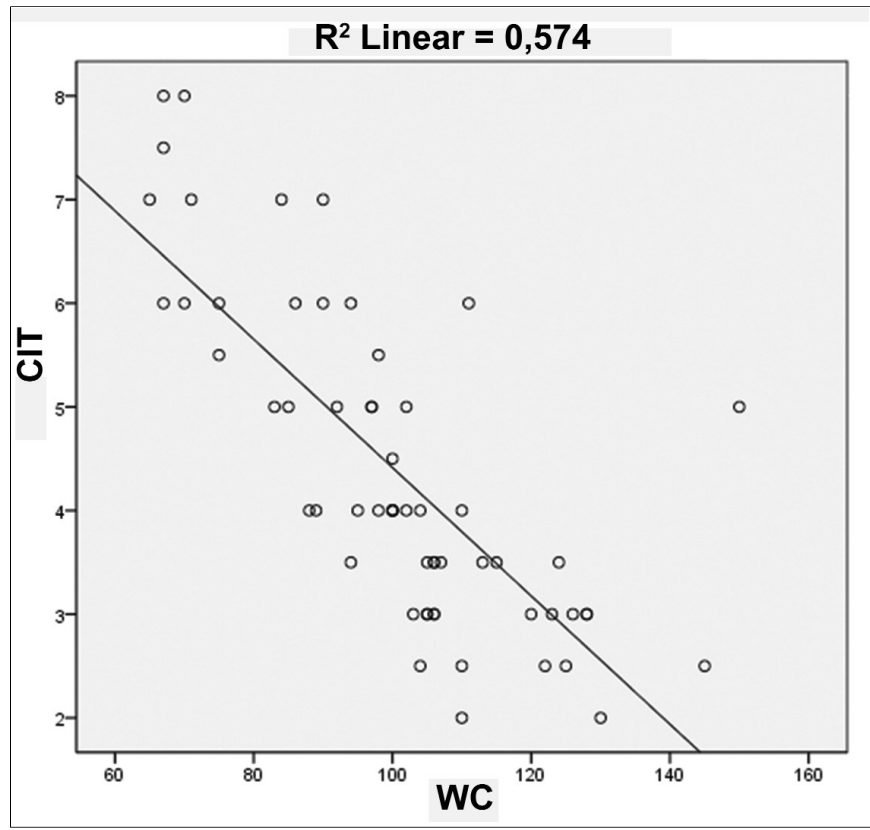

Figure 1: A strong statistically significant negative correlation was found between waist circumference and CIT. level was accepted as $p<0.05$. The Pearson's correlation analysis was run to assess the correlation between waist circumference and CIT.

\section{RESULTS}

All of the subjects were above 18 years of age. The most frequent colonoscopy indications included constipation, anemia, intermittent non-active rectal bleeding, occult blood positivity in feces, and the monitoring of subjects who had underwent a prior polypectomy.

The entire subjects in this study were females with a mean age of $47.7 \pm 14$.6. The mean waist circumference was $100.6 \pm 19.0 \mathrm{~cm}$. The mean CIT was $9.0 \pm 2.7$ minutes. A strong statistically significant negative correlation was found between waist circumference and CIT $(r=-0.689, p<0.001$, Figure 1$)$.

\section{DISCUSSION}

Although a widely accepted scale for obesity, and body mass index is not a true measure of intraabdominal fat, it neither differentiates between fat and muscle, nor between the type and site of fat accumulation. ${ }^{6}$ Waist circumference, on the other hand, is a widely used parameter in describing body weight and abdominal obesity more correctly. However, waist circumference also does not give accurate information on the fat accumulation in the abdominal and retroperitoneal regions. In fact, these regions of accumulated fat are best imaged by computerized tomography, but taking a tomography scan for every patient does not seem practicable.6,7 Therefore, the authors here also preferred using waist circumference, one of the safest and easiest methods, for describing body weights of the colonoscopy subjects included in the study. A strong statistically significant negative correlation was found between waist circumference and CIT in women. This indicates that CIT is to be shorter in subjects with larger waist circumferences, a result that is compatible with the literature data. 1,8

In women, CIT is generally longer and the rate of complete colonoscopy lower.9,10 This is due to the deeper and rounder pelvis which results in greater intrapelvic volume and allows more sigmoid looping during examination. Women also have a longer colon which makes loop formation easy. It is known that women with larger waist circumference have larger abdominal cavity, more visceral fat, and a little more fat accumulation in the retroperitoneal region compared to normal women. The cushions of accumulated fat in this region may allow the colonoscope to move freely at the sharp turns during the colonoscopy procedure, making the CIT shorter. Additionally, the angulations of the sigmoid colon are less sharp and there is more sigmoid mobility in overweight women, letting the colonoscope have an easier passage. More anatomic variations are 
seen in the intestines of women and the colon length, particularly the transverse segment is longer. The fact that overweight subjects have relatively shorter colons than normal may also contribute to the shortening of CIT.4,11

Nagata et al. found in their study that, lower visceral adipose tissue area and lower subcutaneous adipose tissue area are independently associated with longer insertion time and reported that high subcutaneous fat accumulation is the best predictive factor for easier passage of the colonoscope. 7 The factors affecting CIT can actually be divided into patient, technique, and examiner related factors. The patient-related factors include age, gender, body mass index, bowel habitus, colonic diverticular disease, prior abdominal and pelvic surgery, and colon preparation quality. ${ }^{12}$ The techniquerelated factors are the use of medications for sedation and the selection of instruments for the colonoscopy. 13,14

An important factor affecting CIT is colonoscopy experiences of endoscopists and procedure volume.3,13,15 It is obvious that the average CIT an experienced endoscopist can attain during colonoscopies would be much shorter. In this study, the colonoscopies were performed by a single endoscopist to eliminate the endoscopists' experiences.

The results we have obtained at this point have become more specific.

\section{CONCLUSION}

CIT was significantly shorter in female subjects with larger waist circumferences.

\section{REFERENCES}

1. Liang CM, Chiu YC, Wu KL, Tam W, Tai WC, Hu ML, et al. Impact factors for difficult cecal intubation during colonoscopy. Surg Laparosc Endosc Percutan Tech 2012; 22:443-6.

2. Ege B, Bozkaya H, Leventoglu S, Gulen M, Mentes B. Colonoscopy performed according to the quality indicators: Case series. Kolon Rektum Hast Derg 2013; 23:118-23.
3. Jia H, Wang L, Luo H, Yao S, Wang X, Zhang L, et al. Difficult colonoscopy score identifies the difficult patients undergoing unsedated colonoscopy. BMC Gastroenterol 2015; 15:46.

4. Akere A, Otegbayo JA. Complete colonoscopy: Impact of patients' demographics and anthropometry on caecal intubation time. BMJ Open Gastroenterol 2016; 7;3:1.

5. Kim EJ, Kim YJ. Can body mass index predict the difficulty of colonoscopy? Clin Endosc 2016; 49:106-7.

6. Jain D, Goyal A, Uribe J. Obesity and cecal intubation time. Clin Endosc 2016; 49:187-90.

7. Nagata N, Sakamoto K, Arai T, Niikura R, Shimbo T, Shinozaki M, et al. Predictors for cecal insertion time: the impact of abdominal visceral fat measured by computed tomography. Dis Colon Rectum 2014; 57:1213-9.

8. Hsieh $\mathrm{YH}$, Kuo CS, Tseng KC, Lin HJ. Factors that predict cecal insertion time during sedated colonoscopy: the role of waist circumference. J Gastroenterol Hepatol 2008; 23:215-7.

9. Cirocco WC, Rusin LC. Factors that predict incomplete colonoscopy. Dis Colon Rectum 1995; 38:964-8.

10. Church JM. Complete colonoscopy: How often? And if not, why not? Am J Gastroenterol 1994; 89:556-60.

11. Khashab MA, Pickhardt PJ, Kim DH, Rex DK. Colorectal anatomy in adults at computed tomography colonography: normal distribution and the effect of age, sex, and body mass index. Endoscopy 2009; 41:674-8.

12. Jaruvongvanich $V$, Sempokuya $T$, Laoveeravat $P$, Ungprasert $P$. Risk factors associated with longer cecal intubation time: a systematic review and meta-analysis. Int $\mathrm{J}$ Colorectal Dis 2018; 33:359-65.

13. Bernstein C, Thorn M, Monsees K, Spell R, O'Connor JB. A prospective study of factors that determine cecal intubation time at colonoscopy. Gastrointest Endosc 2005; 61:72-5.

14. Hsu CM, Lin WP, Su MY, Chiu CT, Ho YP, Chen PC. Factors that influence cecal intubation rate during colonoscopy in deeply sedated patients. J Gastroenterol Hepatol 2012; 27 : 76-80.

15. Moon SY, Kim BC, Sohn DK, Han KS, Kim B, Hong CW, et al. Predictors for difficult cecal insertion in colonoscopy: The impact of obesity indices. World J Gastroenterol 2017; 23: 2346-54. 